\title{
Task Performance of Midden Workers of Atta sexdens rubropilosa Forel (Hymenoptera: Formicidae)
}

\author{
Fabrícia G. Lacerda • Terezinha M. C. Della Lucia • \\ Og DeSouza • Lucas M. de Souza • \\ Danival J. de Souza
}

Revised: 18 June 2013 / Accepted: 26 June 2013 /

Published online: 12 July 2013

(C) Springer Science+Business Media New York 2013

\begin{abstract}
Material brought to midden piles of leaf-cutting ants is considered to be hazardous. It is therefore expected that midden workers should not re-enter the colony, to reduce pathogen transmission. Here, we examined whether the midden workers of Atta sexdens rubropilosa remain confined to the waste compartment and, if not, whether they could perform many different behaviors in the absence of specialized nestmates. Eleven subcolonies received either midden workers or non-midden workers in addition to pupae and $50 \mathrm{~mL}$ of fungus garden. Survival, fungal and brood care, foraging and waste manipulation were observed daily until subcolonies death. Subcolonies maintained by midden workers died earlier: average survival times were 13.92 and 22.66 days for midden and non-midden workers, respectively. Midden workers cared for the brood and foraged as non-midden workers did but they were not as efficient in caring for the garden. Activities related to waste manipulation were more frequently performed by midden workers. These results show that midden workers are not a behaviorally rigid caste and retain many labor capabilities being able to leave the waste compartment and perform internal activities in the absence of specialized internal workers.
\end{abstract}

Keywords Task performance $\cdot$ leaf-cutting ants $\cdot$ waste management $\cdot$ division of labor

F. G. Lacerda • T. M. C. Della Lucia • O. DeSouza • L. M. de Souza • D. J. de Souza

Departamento de Biologia Animal, Universidade Federal de Viçosa, Viçosa, Brazil

D. J. de Souza $(\bowtie)$

Fundação Universidade Federal do Tocantins, Campus Universitário de Gurupi, Rua Badejós, 77402-970 Gurupi, TO, Brazil

e-mail: danival@uft.edu.br

F. G. Lacerda

Departamento de Biologia, Campus de Alegre, Universidade Federal do Espírito Santo, Alegre, Brazil

O. DeSouza

Departamento de Entomologia, Universidade Federal de Viçosa, Viçosa, Brazil

L. M. de Souza

Embrapa Recursos Genéticos e Biotecnologia, Laboratório de Ecologia e Biossegurança, Brasília, Brazil 


\section{Introduction}

Division of labor in social insects means that individuals within a colony specialize in certain tasks, such as foraging, brood care, nest building or defense. Consequently, each task is performed by particular subsets of workers (Wilson 1971). This specialization has been considered a key factor contributing to the ecological success of social insects (Oster and Wilson 1978). Several factors determine task allocation including genotype, physiology, age, morphology, experience, and social and external environments (Jeanne 1986; Lenoir 1987). Because of this, task allocation has a flexible character that increases colony efficiency (Bonabeau et al. 1998). In the leafcutting ant Atta sexdens, 29 tasks are performed by seven castes, in which specialized workers are mainly distinguished by their behavior rather than by age or anatomy (Wilson 1980).

Transition from one task to another sometimes occurs in workers. This is considered an important mechanism in the organization and ecological success of colonies. A trend found in ants is that younger workers remain in the nest, whereas older workers perform tasks outside, such as foraging and waste management (Wilson 1971). In leaf-cutting ant societies, a group of individuals is involved in waste management. Rejected material may be dangerous to the colony as it contains pathogens (Bot et al. 2001; Hart and Ratnieks 2002; Mueller et al. 2005; Lacerda et al. 2006). An efficient way to minimize the risk of colony infection would be for workers dealing with waste material not to enter the fungus garden. A tight association between age and task may be a problem in unstable conditions, such as highly seasonal or unpredictable environments, or within small colonies (Sendova-Franks and Franks 1993). However, studies have shown that insect societies are more flexible than first thought. Social insect colonies can adjust the numbers of workers engaged in various tasks, such as foraging, nest work and waste management as conditions change (Gordon 1996; Robinson 1992; Waddington and Hughes 2010).

In this study, we examined whether midden workers of Atta sexdens rubropilosa colonies were confined exclusively to the waste compartment. In addition, we tested whether these workers performed other tasks, such as fungal or brood care and foraging, if more specialized workers were absent.

\section{Materials and Methods}

\section{Colony Maintenance}

Eleven A. sexdens rubropilosa colonies of different sizes with populations between 1,500 and 2,500 workers and fungus garden volume ranging from 1 to $2 \mathrm{~L}$ were used to verify whether midden workers were confined to waste piles. Three additional, larger three-year-old A. sexdens rubropilosa colonies (9-10 L of fungus garden) were used to study task performance. Colonies were maintained at $25 \pm 2{ }^{\circ} \mathrm{C}, 75 \pm 3 \%$ R.H. and $12: 12 \mathrm{~h} \mathrm{~L}$ : D and daily supplied with fresh leaves of Acalypha wilkesiana and Ligustrum japonicum and water. 
Behavioral Observations and Assays

\section{Determining Location of Midden Workers in the Nest}

All workers found in the midden of the 11 colonies, except for the minima (the smallest of the workers), were removed and marked on the gaster with non-toxic ink $\left(\right.$ Testors $\left.^{\circledR}\right)$, allowed to dry for one hour, and returned to their original colony. Marking was performed just in this experiment in order to visualize midden workers in the colonies. Minima (Head Width $=0.6$ to $0.8 \mathrm{~mm}$ ) were not marked because they are difficult to detect in the midden. The size distribution of marked workers was similar to that frequently observed in refuse piles $(\mathrm{HW}=0.8-2.0 \mathrm{~mm})$ and they were present in different numbers in each colony. Twenty-four hours later, the number of marked workers found in the midden was counted.

\section{Subcolonies Preparation and Behavioral Asssays}

Portions of colony fungus gardens were removed to create subcolonies (queenless nests). Each subcolony was composed of approximately $50 \mathrm{~mL}$ of garden, from which all ants had been removed. Inside the tray we added leaves of $A$. wilkesiana and L. japonicum and the midden inside $100 \mathrm{~mL}$ plastic vials. The subcolonies were kept under the same conditions as the original colonies. Six subcolonies of each one of the three larger colonies - totalling 18 subcolonies - were prepared; three with only midden workers, and three with non-midden workers. We added to each subcolony of midden workers 50 medium-sized workers $(\mathrm{HW}=1.2-2.0 \mathrm{~mm}), 100$ small workers $(\mathrm{HW}=1.0-1.2 \mathrm{~mm})$ and 150 very small workers $(0.8-1.0 \mathrm{~mm})$, all taken from the refuse pile of the original colony. To the subcolonies of non-midden workers, the same number of additional workers was also added from the original colony. To each subcolony, 40 pupae were added from the original colony. The numbers of intermediate and small ants were proportional to those found in $100 \mathrm{~mL}$ samples of the garden of the original colonies. The number of workers that foraged was also proportional to that found in the foraging arena of the parental colony. The number of pupae added, however, was higher than that usually found in the colonies, because they are fragile and some were expected to die during manipulation.

\section{Behavioral Assays}

Once a day at different hours of the day we observed ant activity for $10 \mathrm{~min}$, including fungus and brood care, foraging and waste manipulation. This was carried out for 25 days. Fungal care was characterized by inspection, grooming, substrate incorporation or hyphae incorporation into the garden. Pupal care was characterized by inspection, transport or grooming. Foraging activity was characterized by leaf-cutting, leaf transport to the colony, and leaf inspection. Waste manipulation was defined as dwelling (waste arrangement and construction of tunnels), excavation or transport of waste. Behavioral acts were observed; not the number of workers performing them.

These observations were conducted until the subcolony died or the fungus garden was destroyed. For each behavioral act we calculated a proportion based on the number of days workers were seen performing the activity and the total number of observation days. So, if small workers maintained the garden on five 
days out of a total of 25 observation days, the time proportion was $5 / 25=0.2$. The same methodology was used to calculate brood care, waste management and foraging. In foraging, we did not measure worker size because foraging in such small subcolonies may take some time to occur (in some days there may not occur at all). So, foraging was characterized by the presence or absence of fresh vegetable in the fungal garden.

\section{Survival and Statistical Analyses}

Survival analyses with Weibull distributions were performed (Crawley 2002) on the data of waste and non-waste worker sub-colonies using the 'survival' package of the program R (R Development Core Team 2006; Therneau 1999). The general equation was:

$$
S(t)=e^{\left\{-\left[\left(\mu^{\wedge}(-\alpha t)^{\wedge} \alpha\right)\right]\right\}},
$$

where $\mathrm{S}(\mathrm{t})=$ proportion of live sub-colonies as a function of time; $\mu=$ average time until death, e.g. the lapse of time necessary for the death of $50 \%$ of the colony; $\alpha=$ curve shape, regarding each of the three situations; $\alpha=1$ describes constant mortality, e.g. in each unit of time the same quantity of individuals die; $\alpha>1$ describes the mortality rate increasing with time, e.g. in each unit of time more individuals die than in the previous unit; $\alpha<1$ describes a reduction in the mortality rate.

All behavioral acts were subjected to nested analysis of variance (ANOVA) with fixed factors represented by the variable treatment (waste or non-waste workers) and random factors represented by the variable worker castes (very small, small and medium workers) nested within colony and sub-colony.

\section{Results}

\section{Location of Midden Workers Inside the Nest}

Twenty-four hours after being marked and released, from 562 marked midden workers, only $94(16.7 \%)$ were detected again in the refuse pile. We verified that other tasks, such as foraging ( 22 workers) and fungal care ( 5 workers), were performed by the marked midden workers in the colonies.

\section{Task Performance}

\section{Survival and Colony Maintenance}

The survival analyses of the subcolonies of the two treatments (gardeners and foragers maintained/gardeners and foragers replaced by midden workers) showed that, in the second case, subcolonies where midden workers performed gardening and foraging died earlier than subcolonies where non-midden workers performed those tasks (Fig. 1). The mean time until death of subcolonies maintained by non-midden workers $(\mu)$ was 22.66 days, whereas that maintained by midden workers was 13.92 days. Thus, the curve equations of subcolonies of midden and non-midden 


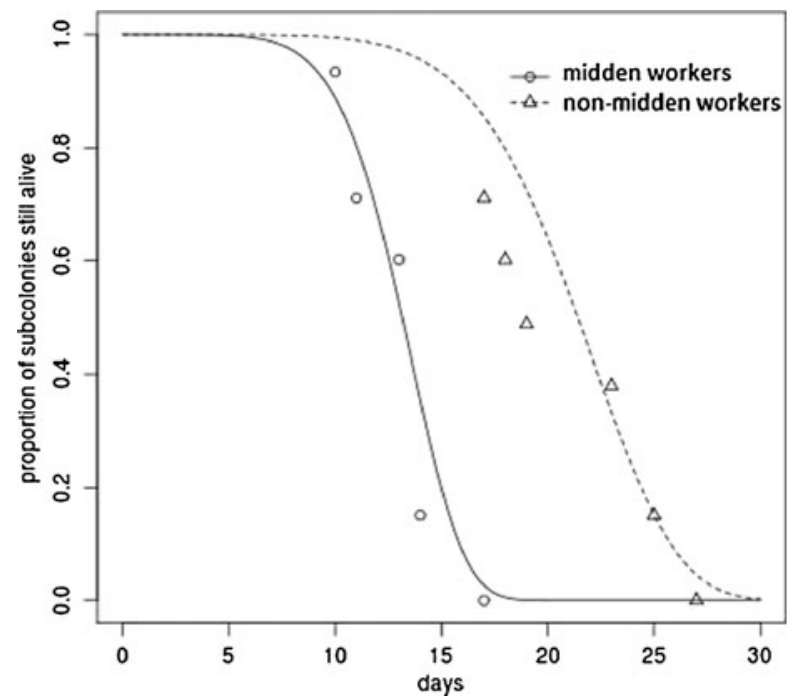

Fig. 1 Survival curves of subcolonies of Atta sexdens rubropilosa maintained by waste and non-waste workers

workers were $\mathrm{S}(\mathrm{t})=\mathrm{e}^{[-13.92(-6.45 \mathrm{xt6.45)})}$ and $\mathrm{S}(\mathrm{t})=\mathrm{e}^{[-22.66(-6.45 \mathrm{xt} 6.45)]}$, respectively. The two curves were statistically different $(p<0.0001)$.

Midden workers have the ability to take care of the fungus garden, even if they do it significantly less frequently than non-midden workers $\left(F_{1,14}=4.87, P=0.04\right)$ (Fig. 2). Midden workers were observed caring for pupae $\left(F_{1,14}=3.52, P=0.08\right)$ and foraging $\left(F_{1,14}=0.03, P=0.87\right)$ at the same frequency as non-midden workers. Midden workers manipulated refuse significantly more frequently than non-midden workers $\left(F_{1,14}=11.71, P<0.01\right)$ (Fig. 3).

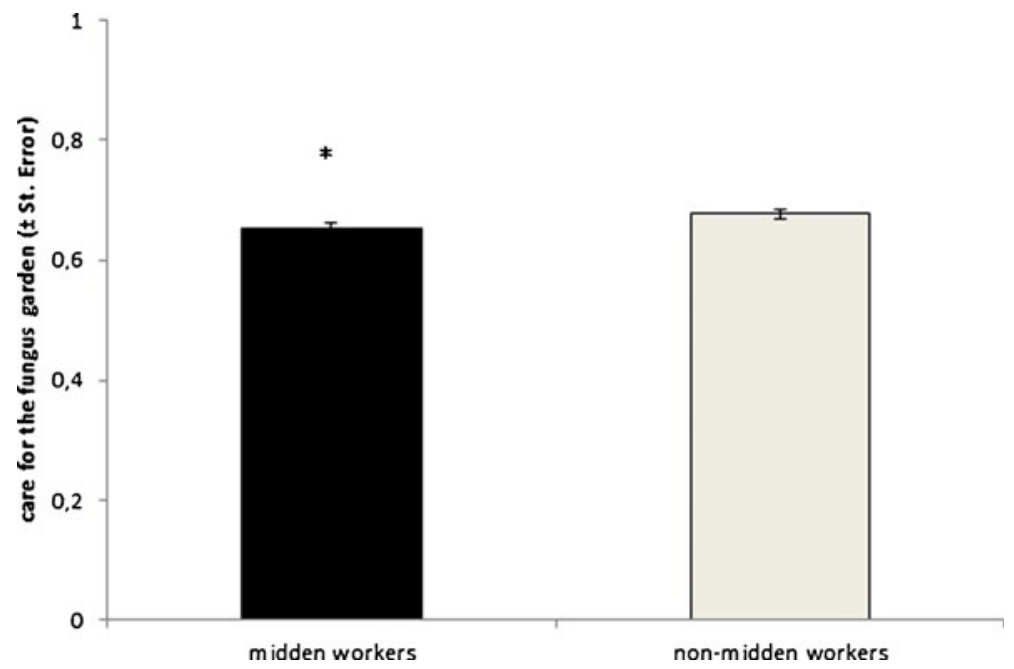

Fig. 2 Fungus garden care by midden and non-midden (fungus garden workers and foragers). Care was measured by the proportion of times that workers were observed caring for the garden in relation to the total of observations. Midden workers cared for the fungus garden less frequently than non-midden workers $\left(F_{1,14}=4.87, P=0.04\right)$ 


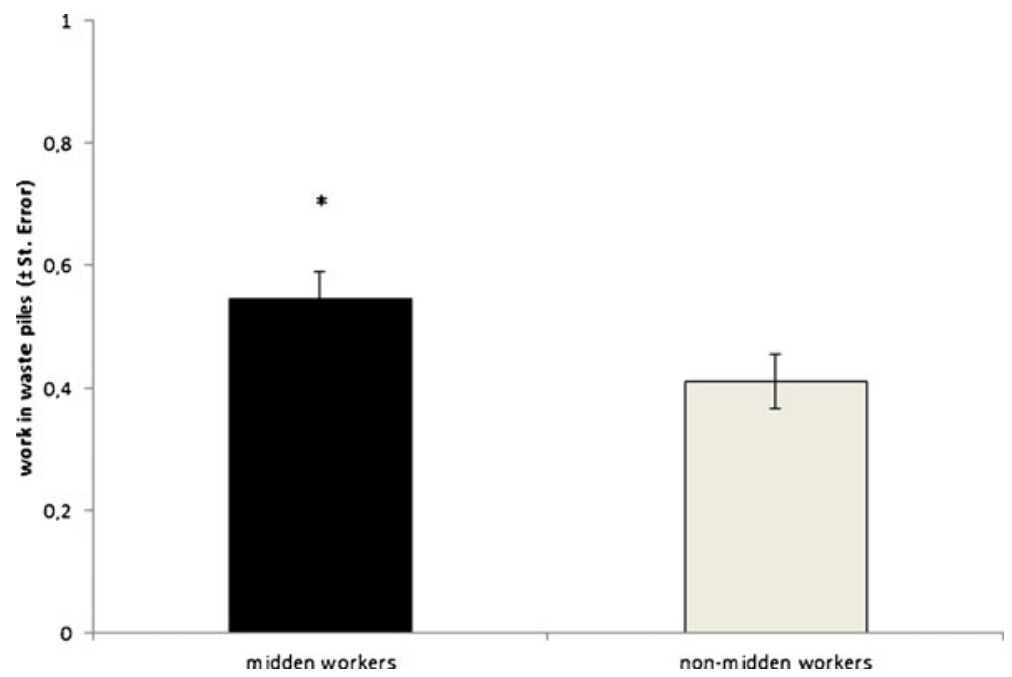

Fig. 3 Waste management by midden and non-midden workers (fungus garden workers and foragers). Waste management was measured by the proportion of times workers were observed dealing with refuse in relation to the total observations. The frequency of midden workers manipulation refuse was higher than the frequency of non-waste workers $\left(F_{1,14}=11.71, P<0.01\right)$

\section{Discussion}

Midden workers of $A$. sexdens rubropilosa did not remain confined to the waste compartment, performing other activities, such as foraging and fungal care. Since the colonies used in this experiment had large volume of fungus garden the majority of the marked midden workers could not be recovered. Therefore, we assumed that they moved to the interior of the fungus garden and were not seen in the foraging arena. The lack of ants recovered in the waste pile could not be due to mortality because they were not recovered on the midden in the following days after the experiment. Also, loss of mark could not account for the lack of ant recovery because we have verified in previous experiments that the ink lasts for over three weeks. In this case, the presumed colony compartmentalization was not rigid, as a considerable part of midden workers returned to nest interior despite risks of colony contamination. Although evidence of previous studies (Hart and Ratnieks 2001) that midden workers are excluded from the fungus and other nest areas, our observations point toward different directions. Maybe the midden workers are not excluded from internal activities when they do not represent a risk to the colonies, e. g. they would not carry virulent pathogens to the colonies. Little is known about the function of midden workers and why they engaged in waste manipulation of the colony. Further research is needed to elucidate these features.

Midden workers performed internal activities in the absence of internal workers; however, the colonies were less well maintained. They exhibited brood care at a similar frequency to non-midden workers, confirming that they are able to play other roles in the colony. Their success can be estimated by the fact that in all subcolonies, new adults were seen (i.e. emerged from pupae placed in each subcolony). Pupal care is highly conspicuous in ant colonies, and whenever a colony is disturbed, a common behavior is to transport larvae and pupae (Hölldobler and Wilson 1990). Brood care is 
an important task in the colony, so it would be advantageous if all workers could participate, independent of their caste.

Perturbations, such as diminishing colony size or number of nest maintenance workers, may have driven midden workers to switch activities. An important point to consider in our study is the impact of colony reduction in worker behavior, as we obtained smaller subcolonies from larger colonies. It has been hypothesized that younger colonies exhibit more task flexibility (Lenoir 1979a). Considering that small colonies behave like younger colonies and being colony size an attribute more important than colony age in determining worker allocation in Atta (Wilson 1983), we can suppose that task switching may be more likely to occur in small colonies where fluctuation in worker numbers is more dramatic. As the colony increases its size, behavioral plasticity may become reduced.

Other studies have indicated that nest maintenance workers switch out of that task more frequently than others switch into it (Gordon 1989; Waddington and Hughes 2010). If more nest maintenance workers are needed, they are generally recruited from the reserve of young workers inside the nest (Lenoir 1979b; Porter and Jorgensen 1981; Weir 1958a, 1958b). However, our study indicates that midden workers also could be recruited to other activities if necessary.

It is likely that there exists a certain direction in the activities developed by the workers in their lifetime, driven by age polyethism, but it is possible that behavioral plasticity occurs when necessary due to a change in the social environment. Factors that lead a worker to deal with the waste in A. sexdens rubropilosa have not been completely elucidated. Apparently, waste activities are an additional task outside the colony and, as such do not require individual specialization. Thus, generalist workers may be advantageous to leaf-cutter colonies. Midden workers therefore are not behaviorally rigid caste; they retain many labor capabilities.

Acknowledgments Thanks to Prof. Dr Ricardo Della Lucia for a critical reading of this manuscript and to Karina Amaral for helping with worker measurement. We are also thankful to CNPq for the scholarships, especially for the grant 474819/2006-0.

\section{References}

Bonabeau E, Theraulaz G, Deneubourg JL (1998) Fixed response thresholds and the regulation of division of labor in insect societies. Bull Math Biol 60:753-807

Bot ANM, Currie CR, Hart AG, Boomsma JJ (2001) Waste management in leaf-cutting ants. Ethol Ecol Evol 13:225-237

Crawley MJ (2002) Statistical Computing: An introduction to data analysis using S-Plus. John Wiley \& Sons, New York

Gordon DM (1989) Dynamics of task switching in harvester ants. Anim Behav 38:194-204

Gordon DM (1996) The organization of work in social insect colonies. Nature 380:121-124

Hart AG, Ratnieks FLW (2001) Task partitioning, division of labour and nest compartmentalization collectively isolate hazardous waste in the leaf-cutting ant Atta cephalotes. Behav Ecol Sociobiol 49:387-392

Hart AG, Ratnieks FLW (2002) Waste management in the leaf-cutting ant Atta colombica. Behav Ecol $13: 224-231$

Hölldobler B, Wilson EO (1990) The ants. Harvard University Press, Cambridge

Jeanne RL (1986) The evolution of the organization of work in social insects. Monit Zool Ital 20:119-134 
Lacerda FG, Della Lucia TMC, Lima E, Campos LAO, Pereira OL (2006) Waste management by workers of Atta sexdens rubropilosa (Hymenoptera: Formicidae) in colonies supplied with different substrates. Sociobiology 48:165-173

Lenoir A (1979a) Le comportement alimentaire et la division du travail chez la fourmi Lasius niger (L.). Bull. Biol. France et Belg 113:79-314

Lenoir A (1979b) Feeding behaviour in young societies of the ant Tapinoma erraticum L.: trophallaxis and polyethism. Insect Soc 26:19-37

Lenoir A (1987) Factors determining polyethism in social insects. In: Pasteels JM, Deneubourg JL (eds) From individual to collective behavior in social insects, les Treilles Workshop. Birkhauser, Basel, pp 219-240

Mueller UG, Gerardo NM, Aanen DK, Six DL, Schultz TR (2005) The evolution of agriculture in insects. Ann Rev Ecol Syst 36:563-595

Oster GF, Wilson EO (1978) Caste and ecology in the social insects. Princeton University Press, Princeton

Porter SD, Jorgensen CD (1981) Foragers of the harvester ant, Pogonomyrmex owyheei: a disposable caste? Behav Ecol Sociobiol 9:247-256

R Development Core Team (2006) R: A language and environment for statistical computing. R Foundation for Statistical Computing, Vienna

Robinson GE (1992) Regulation of dvision of labor in insect societies. Ann Rev Entomol 37:637-665

Sendova-Franks A, Franks NR (1993) Task allocation in ant colonies within variable environments (A study of temporal polyethism, experimental). Bull Math Biol 55:75-96

Therneau TM (1999) A package for survival analysis in S. (The survival package is available in the CRAN library: http://cran.r-project.org/web/packages/survival/index.html)

Waddington SJ, Hughes WOH (2010) Waste management in the leaf-cutting ant Acromyrmex echinatior: the role of worker size, age and plasticity. Behav Ecol Sociobiol 64:1219-1228

Weir JS (1958a) Polyethism in workers of the ant Myrmica. I Insect Soc 5:97-128

Weir JS (1958b) Polyethism in workers of the ant Myrmica. II Insect Soc 5:315-339

Wilson EO (1971) The insect societies. Harvard University Press, Cambridge

Wilson EO (1980) Caste and division of labor in leaf-cutter ants (Hymenoptera: Formicidae: Atta). I. The overall pattern in Atta sexdens. Behav Ecol Sociobiol 7:143-156

Wilson EO (1983) Caste and division of labor in leaf-cutter ants (Hymenoptera: Formicidae: Atta) IV. Colony ontogeny of $A$. cephalotes. Behav Ecol Sociobiol 14:55-60 